\title{
Clinicopathological Evaluation of Surgical Treatment for Early Gallbladder Cancer
}

\author{
HISAFUMI KINOSHITA, KOTARO HASHINO, MITSUO HASHIMOTO, TAKAHITO KODAMA, \\ KAZUNORI NISHIMURA, MASAHIRO KAWABATA, SATOSHI FURUKAWA, \\ TSUYOSHI TAMAE, JUN NAGASHIMA, MASAO HARA, \\ HIROYASU IMAYAMA AND SHIGEAKI AOYAGI \\ Department of Surgery, Kurume University School of Medicine, \\ Kurume 830-0011, Japan
}

\begin{abstract}
Summary: We evaluated the therapeutic principles for early gallbladder cancer based on clinicopathological characteristics and outcomes in 27 patients encountered at the Kurume University Hospital between January, 1975 and December, 1999. Concerning the depth of wall penetration, 15 patients had mucosal cancers (m-cancers), and 12 patients muscularis propria cancers(mpcancers). The gross patterns were Ip (pedunculated) in 16 patients, Is (sessile) in 3 patients, Ila (flat elevated) in 4 patients, and Illb (flat) in 4 patients. The operative procedure used was cholecystectomy $(C)$ in 12 patients, 4 of whom underwent lymph node dissection. Full-thickness cholecystectomy (FTC) was carried out in 3 patients, one of whom had lymph node dissection. Combination of $C$ and gallbladder bed resection (GbBR) was performed in 7 patients, 6 of whom had lymph node dissection. Combination of $C$ and bile duct resection (BDR), and lymph node dissection was performed in 1 patient. Combination of $C$ and GbBR and BDR, and lymph node dissection was performed in 6 patients. All the patients who underwent lymph node dissection were negative for metastasis. Of the 27 patients, 2 underwent laparoscopic operation: one with m-cancer was 79 years old, and the other with mp-cancer 86 years old. In the m-cancers, no lymphatic, venous or perineural infiltration was observed. In contrast, in the mp-cancers, lymphatic and venous infiltration each were observed in 4 patients (33.3\%), although no perineural infiltration was observed. A diagnosis of gallbladder cancer was made postoperatively in 6 patients, of whom 4 had the $\mathrm{Ilb}$ pattern and all were complicated by gallstone, indicating the difficulty of diagnosing the $\mathrm{llb}$ pattern. The 5-year survival rates for the $\mathrm{m}$ - and mp-cancers were as high as $90.9 \%$ and $80.8 \%$, respectively. As a curative surgical technique for $\mathrm{m}$ - and $\mathrm{mp}$-cancers, lymph node dissection should be performed in addition to FTC, GbBR, and BDR, in combination. When a postoperative histopathologic diagnosis of gallbladder cancer has been made, no second-look operation should be performed for m-cancers, but lymph node dissection of up to the second group should be performed for $\mathrm{mp}$-cancers in a second-look operation.
\end{abstract}

Key words gallbladder cancer, early cancer, operative procedure

\section{INTRODUCTION}

Thanks to various kinds of diagnostic imaging including ultrasonography, the chances of detecting early cancers have increased. However, a review of patients undergoing resection of gallbladder cancers shows a low detection rate. Early cancer of the gall- bladder is often found by postoperative histopathologic examination, and cases of recurrence have been reported. Therefore, the therapeutic strategy for early cancers varies in different institutions. In this study, we evaluated the therapeutic principles for early gallbladder cancer based on the clinicopathological characteristics and outcomes of cases encountered at the Kurume University Hospital. We described the 
histologic findings in accordance with the Japanese society of biliary surgery [1] and calculated the cumulative survival rate using Kaplan-Meier's method.

\section{SUBJECTS AND METHODS}

Our department performed 145 resections for gallbladder cancer in the period from January 1975 to December 1999. In 27 early gallbladder cancers, we evaluated gross patterns, histologic features of cancer progression, operative procedures, and longterm results.

\section{RESULTS}

Early cancers accounted for $18.6 \%$ of all the gallbladder cancers, including 15 cases of m-cancer and 12 cases of mp-cancer. They were diagnosed preoperatively, intraoperatively and postoperatively in 20 , 1 and 6 cases, respectively (Table 1). In 19 of the 20 preoperatively diagnosed cases, the tumors had a diameter of $14 \mathrm{~mm}$ or over. Grossly, the protuberant type was observed in 19 cases: the breakdown was 16 cases of Ip and 3 cases of Is. The superficial type was observed in 8 cases: the breakdown was 4 cases of IIa and 4 cases of IIb. The Ip pattern accounted for $60.0 \%$ (Table 2). These tumors measured, in diameter, $5 \mathrm{~mm}$ or below in 1 case, $6-10 \mathrm{~mm}$ in 3 cases, $11-20 \mathrm{~mm}$ in 8 cases, and $21 \mathrm{~mm}$ or over in 13 cases accounting for more than half of the cases (Table 3 ).

TABLE 1.

Diagnosis

\begin{tabular}{cc}
\hline Diagnosis & No. of patients \\
\hline Preoperative diagnosis & 20 \\
Intraoperative diagnosis & 1 \\
Postoperative diagnosis & 6 \\
\hline Total & 27 \\
\hline
\end{tabular}

TABLE 2

Gross patterns

\begin{tabular}{cc}
\hline Gross pattern & No. of patients \\
\hline Protuberant type (TypeI) & 19 \\
Ip & 16 \\
Is & 3 \\
Superficial type (Type II) & 8 \\
IIa & 4 \\
IIb & 4 \\
\hline \multicolumn{2}{c}{ Total } \\
\hline
\end{tabular}

The breakdown of the operative procedures was as follows: cholecystectomy in 12 cases, in 4 of which lymph node dissection was performed; combination of $\mathrm{C}$ and GbBR in 7 cases, in 6 of which lymph node dissection was performed; combination of $\mathrm{C}$ and $\mathrm{BDR}$, and lymph node dissection in 1 case; and combination of $\mathrm{C}$ and GbBR and BDR, and lymph node dissection in 4 cases (Table 4). All the 16 patients undergoing lymph node dissection were negative for metastasis. Laparoscopic operation was performed on 2 of the 27 patients, a 79-year-old patient with mcancer and an 86-year-old patient with mp-cancer. The growth patterns of tumors infiltrating the surrounding tissue was INF $\alpha$ in all cases of m-cancer; INF $\alpha$ in 7 cases of mp-cancer and INF $\beta$ in 4 cases of mp-cancer; and INF $\gamma$ in no cases (Table 5). Neither

TABLE 3.

Tumor size

\begin{tabular}{cc}
\hline Tumor size & No. of patients \\
$\leqq 5 \mathrm{~mm}$ & 1 \\
$6-10 \mathrm{~mm}$ & 3 \\
$11-20 \mathrm{~mm}$ & 8 \\
$\geqq 21 \mathrm{~mm}$ & 13 \\
Unknown & 2 \\
\hline Total & 27 \\
\hline
\end{tabular}

TABLE 4.

Operative procedures

\begin{tabular}{lcc}
\hline \multicolumn{1}{c}{ Operative procedure } & $\begin{array}{c}\text { m-cancer } \\
(\mathrm{n}=15)\end{array}$ & $\begin{array}{c}\text { mp-cancer } \\
(\mathrm{n}=12)\end{array}$ \\
\hline $\mathrm{C}$ & 5 & 3 \\
$\mathrm{C}+\mathrm{D}$ & 2 & 2 \\
FTC & 1 & 1 \\
FTC + D & 1 & 0 \\
$\mathrm{C}+\mathrm{GbBR}$ & 1 & 0 \\
$\mathrm{C}+\mathrm{GbBR}+\mathrm{D}$ & 3 & 3 \\
$\mathrm{C}+\mathrm{BDR}+\mathrm{D}$ & 1 & 0 \\
$\mathrm{C}+\mathrm{GbBR}+\mathrm{BDR}+\mathrm{D}$ & 1 & 3 \\
\hline
\end{tabular}

D: lymph node dissection

TABLE 5.

Growth patterns of tumors infiltrating the surrounding tissue (INF)

\begin{tabular}{lcc}
\hline INF & $\begin{array}{c}\text { m-cancer } \\
(\mathrm{n}=15)\end{array}$ & $\begin{array}{c}\text { mp-cancer } \\
(\mathrm{n}=12)\end{array}$ \\
\hline INF $\alpha$ & 15 & 7 \\
INF $\beta$ & 0 & 4 \\
Unknown & 0 & 1 \\
\hline
\end{tabular}


TABLE 6.

Vascular infiltration

Lymphatic infiltration (ly)

\begin{tabular}{lcccccc}
\hline $\begin{array}{l}\text { Depth of wall } \\
\text { penetration }\end{array}$ & $l y(-)$ & $l y(+)$ & $1 y_{1}$ & $l y_{2}$ & $l y_{3}$ & Unknown \\
\hline m-cancer (n=15) & 15 & $\begin{array}{c}0 \\
(0)\end{array}$ & 0 & 0 & 0 & 0 \\
mp-cancer $(n=12)$ & 8 & $\begin{array}{c}4 \\
(33.3)\end{array}$ & 4 & 0 & 0 & 0 \\
ss-cancer (n=54) & 11 & $\begin{array}{c}40 \\
(78.4)\end{array}$ & 16 & 22 & 2 & 3 \\
\hline
\end{tabular}

( ): $\%$

Venous infiltration (v)

\begin{tabular}{lcccccc}
\hline $\begin{array}{l}\text { Depth of wall } \\
\text { penetration }\end{array}$ & $\mathrm{v}(-)$ & $\mathrm{v}(+)$ & $\mathrm{v}_{1}$ & $\mathrm{v}_{2}$ & $\mathrm{v}_{3}$ & Unknown \\
\hline m-cancer (n=15) & 15 & $\begin{array}{c}0 \\
(0)\end{array}$ & 0 & 0 & 0 & 0 \\
mp-cancer (n=12) & 8 & $\begin{array}{c}4 \\
(33.3) \\
39\end{array}$ & 4 & 0 & 0 & 0 \\
ss-cancer (n=54) & 12 & $\begin{array}{c}39 \\
(76.5)\end{array}$ & & & 5 & 3 \\
\hline
\end{tabular}

( ): $\%$

TABLE 7.

Perineural infiltration (pn)

\begin{tabular}{lcccccc}
\hline $\begin{array}{l}\text { Depth of wall } \\
\text { penetration }\end{array}$ & $\mathrm{pn}(-)$ & $\mathrm{pn}(+)$ & $\mathrm{pn}_{1}$ & $\mathrm{pn}_{2}$ & $\mathrm{pn}_{3}$ & Unknown \\
\hline m-cancer $(\mathrm{n}=15)$ & 15 & $\begin{array}{c}0 \\
(0)\end{array}$ & 0 & 0 & 0 & 0 \\
mp-cancer $(\mathrm{n}=12)$ & 12 & $\begin{array}{c}0 \\
(0)\end{array}$ & 0 & 0 & 0 & 0 \\
ss-cancer (n=54) & 27 & $\begin{array}{c}24 \\
(47.1)\end{array}$ & 9 & 12 & 3 & 3 \\
\hline
\end{tabular}

( ): $\%$

TABLE 8.

Gross patterns

-postoperative diagnosis-

\begin{tabular}{cc}
\hline Gross pattern & No. of patients \\
\hline Ip & 2 \\
IIb & 4 \\
\hline Total & 6 \\
\hline
\end{tabular}

lymphatic nor venous infiltration was observed in the $\mathrm{m}$-cancers, while lymphatic and venous infiltration each were noted in 4 cases $(33.3 \%)$ of mp-cancer. Subserosal-cancers (ss-cancers) showed marked lymphatic and venous infiltration (Table 6). Neither m-

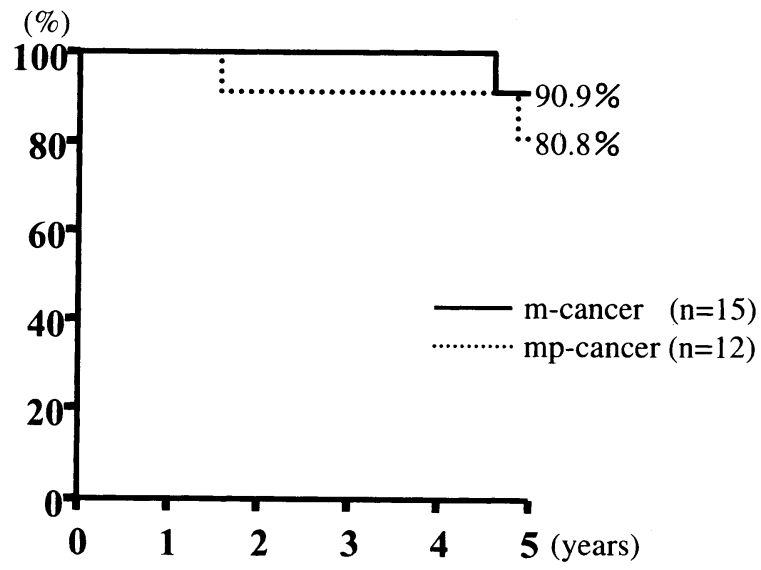

Fig. 1. Cumulative survival rates for early cancers.

nor mp-cancers showed perineural infiltration, while over half of the ss-cancers did (Table 7). Postoperative diagnoses were made in 6 cases: 5 cases of $\mathrm{m}$-cancer and 1 case of mp-cancer. In 1 case, reoperation with lymph node dissection was performed before the depth of wall penetration was determined by postoperative histopathologic examination because of the young age of the patient. However, retrospectively, the depth of wall penetration did not necessitate the reoperation. The patient with mp-cancer, who did not consent to reoperation, has been followed for over 15 years and been alive without any sign of recurrence. The gross patterns of the 6 postoperatively diagnosed cancers were Ip in 2 cases and IIb in 4 cases (Table 8). One of the Ipcancers had been diagnosed as a poly with a diameter of $5 \mathrm{~mm}$. The other Ip-cancer could not be diagnosed preoperatively and was recognized as a 7-mm tumor during operation. All the postoperatively diagnosed cancers were complicated by gallstone. The cumulative survival rates for early cancers showed a good prognosis: the 5-year survival rates for $\mathrm{m}$ - and $\mathrm{mp}$ cancers were $90.9 \%$ and $80.8 \%$, respectively (Fig. 1). Seven patients died: 1 patient during hospitalization and the other 6 of other diseases. No patient with early cancer died of recurrent cancer.

\section{DISCUSSION}

Early gallbladder cancers refer to those cases in which the histologic depth of wall penetration is limited to the mucosa or the muscular propria, irrespective of lymph node metastasis. However, intraepithelial cancers within Rokitansky-Aschoff sinuses 
were defined as intramucosal cancers, whichever layer they were located in [2]. Gallbladder cancers are anatomically characterized by the absence of the lamina muscularis mucosae and the presence of the Rokitansky-Aschoff sinus. Thus, the mode of progression of gallbladder cancer is variable, and the operative procedure, even for early gallbladder cancer, has not been established. The depth of wall penetration is the most important factor determining the prognosis of gallbladder cancer. The prognosis of $\mathrm{m}$-cancers within the mucosa and mp-cancers within the muscularis is favorable. However, although in some cases of $\mathrm{m}$ - and $\mathrm{mp}$-cancers death due to postoperative recurrence did not occur [3-5], a few deaths due to recurrence have been reported [6-11]. In our series of cases, we did not encounter an mcancer progressing to lymph node metastasis, or lymphatic, venous or perineural infiltration. We therefore consider that cholecystectomy alone effects a permanent cure. Although it has been reported that even mp-cancers have a good prognosis after cholecystectomy alone [12], we consider that cholecystectomy alone is insufficient for cure, because in our series we observed lymphatic and venous infiltration in $33.3 \%$ of the mp-cancers despite the absence of lymph node metastasis and perineural infiltration. In their series of gallbladder cancers, Mizumoto et al. [13] observed lymph node metastasis, lymphatic infiltration, and venous infiltration in $15.7 \%, 18.4 \%$ and $8.7 \%$ of mp-cancers, respectively. Uchino et al. [14] have indicated the need for lymph node dissection, because some patients with mp-cancer undergoing cholecystectomy alone developed recurrence in lymph nodes, and because it is difficult to accurately assess the depth of wall penetration even by a rapid frozen section technique during operation. Uchimura et al. [15] also observed lymphatic infiltration in 2 cases of mp-cancer, and have stated that systematic lymph node dissection is needed if infiltration beyond the bounds of mp-cancers is present. At present, it is difficult to reliably distinguish mfrom mp-cancers even by ultrasonic endoscopy, intraoperative ultrasonography, or intraoperative rapid histopathologic examination, and the distinction depends solely on the postoperative examination of the whole gallbladder specimen. Therefore, as a curative surgical procedure for $\mathrm{m}$ - and $\mathrm{mp}$-cancers, cholecystectomy alone is insufficient and, in addition to a combination of full-thickness cholecystectomy, gallbladder bed resection, and bile duct resection, lymph node dissection up to the second group should be performed [16]. Many postoperatively diagnosed cancers represent the IIb pattern, which is difficult to delineate by diagnostic imaging. In addition, a gallstone complication poses a problem as a factor making preoperative diagnostic imaging difficult. The IIb pattern is often found incidentally by postoperative histopathologic examination in a patient operated on for erroneously diagnosed gallbladder stone. In our series, all the patients with postoperatively diagnosed cancer had a gallstone complication, and 4 of the 6 patients had the IIb pattern. Watanabe et al. [17] reported the importance of intraoperative gross findings and observation under the stereoscopic microscope in the detection of IIb lesions. The question arises of whether or not second-look operation should be performed for postoperatively diagnosed cancers. Yoshida et al. [18] state that it is appropriate not to perform second-look operation for m-cancers, but recommend second-look operation for mp-cancers if the patient is relatively young and is in good condition. The therapeutic strategy of our department is that we do not perform a second-look operation for $\mathrm{m}$-cancers but do perform lymph node dissection of up to the second group in a second-look operation for mp-cancers. We consider that if a cancer is located at the gallbladder bed, combined resection of the adjacent liver should be performed, and that combined resection of the bile duct needs to be done for cancers occupying the neck of the gallbladder or the cystic duct. Recently, laparoscopic operation has often been performed for biliary tract disease. In gallbladder cancers that have been discovered after laparoscopic cholecystectomy, the risk of metastasis to trocar sites and the peritoneum by dissemination has been reported. Since even an early cancer can recur, we consider that if gallbladder cancer is suspected preoperatively or if a cancer is suspected during laparoscopic cholecystectomy, laparotomy should be performed.

\section{REFERENCES}

1. Japanese Society of Biliary Surgery. General rules for surgical and pathological studies on cancer of biliary tract, The 4th edition, Kanehara, Tokyo, Japan, 1997.

2. Japanese Society of Biliary Surgery. General rules for surgical and pathological studies on cancer of biliary tract, The 3rd edition, Kanehara, Tokyo, Japan, 1993.

3. Yokomizo S, Nakayama T, and Nishimura S. Surgical treatment of gallbladder carcinoma confined within mucosa or muscle layer. J Bil Panc 1987; 8:1091-1095. (in Japanese)

4. Ohta T, Nagakawa T, Ueno K, Ueda N, Miyazaki I et al. Problems of radical operation for advanced carcinoma of 
the gallbladder in view of mudes of cancer spread. J Bil Panc 1989; 10:797-801. (in Japanese)

5. Uchimura M, Muto Y, and Waki S. Controversy on early carcinoma of the gallbladder based on the results of surgical treatment. J Jpn Surg Soc 1985; 86:1085-1088. (in Japanese)

6. Kakita A, Tkahashi T, Kanbayashi T, Tsuburaya T, and Funaki S. Treatment of gallbladder carcinoma in early stage. Jpn J Gastroenterol Surg 1985; 18:883-886. (in Japanese)

7. Koyama K, and Sato T. Surgical problems of early cancer of the gallbladder. Jpn J Gastroenterol Surg 1985; 18:875-882. (in Japanese)

8. Kimura W, and Shimada H. A case of gallbladder carcinoma with infiltration into the muscular layer that resulted in relapse and death from metastasis to the liver and lymphnodes. Hepatogastroenterology 1990; 31:5689.

9. Tsunoda $\mathrm{T}$, Yamamoto $\mathrm{K}$, Yamaguchi $\mathrm{T}$, Izawa $\mathrm{K}$, Tsuchiya $\mathrm{R}$ et al. Diagnosis and treatment of early carcinoma of gallbladder and extrahepatic bile duct. Jpn J Gastroenterol Surg 1985; 18:887-890. (in Japanese)

10. Bivins BA, Meeker WR, Weiss DL, and Griffen WO. Carcinoma in situ of the gallbladder: A Dilemma. South Med J 1975; 68:297-300.

11. Kott I, and Urea I. Carcinoma in situ of the gallbladder and routine cholecystectomy. Med Chir Diag 1974;
3:181-192.

12. Nevin JE, Moran TJ, Kay S, and King R. Carcinoma of the gallbladder. Staging, treatment and prognosis. Cancer 1975; 37:141-148.

13. Mizumoto R, Ogura Y, Matsuda S, Kusuda T, Taoka H et al. Cooperative survey of surgical treatment for carcinoma of the biliary tract in Japan. J Bil Panc 1990; 11:869-882. (in Japanese)

14. Uchino J, Saji Y, kakita A, Takahashi T, Kanbayashi M et al. Gallbladder carcinoma in the early stage. Gastroenterological Surg 1986; 9:9-15 (in Japanese)

15. Uchimura M, Waki S, Kanda K, Narita K, Okamoto K et al. Surgical strategy for early carcinoma of the gallbladder. J Bil Panc 1990; 11:1129-1135. (in Japanese)

16. Kinoshita M, Nakayama T, Imayama $\mathrm{H}$, and Okuda $\mathrm{K}$. Diagnosis of extention and treatment of carcinoma of the gallbladder. J Jpn Surg Soc 1999; 99:700-705. (in Japanese)

17. Watanabe $Y$, Shirai $M$, Iwafuchi $M$, Ishihara $N$, and Yoshida K. Subjects of pathological study on carcinoma of the gallbladder. Stomach and Intestine 1983; 18:10491054. (in Japanese)

18. Yoshida K, Tsukada K, Shirai Y, Uchida K, Kurosaki I et al. Surgical strategy for early cancer of the gallbladder. J Clin Surg 1989; 44:1731-1736. (in Japanese) 